\title{
Prevalence of timely breastfeeding initiation and associated factors in Dembecha district, North West Ethiopia: a cross-sectional study
}

\author{
Abebe Bimerew ${ }^{1}$, Muluken Teshome ${ }^{2}$ and Getachew Mullu Kassa ${ }^{3 *}$
}

\begin{abstract}
Background: Early initiation of breastfeeding is a simple and cost effective intervention to advance the health of mothers and newborn babies. A large number of neonatal deaths could be prevented if infants were breastfed. However, there is poor practice related to breastfeeding initiation within the first one hour of birth, and the factors affecting it are not well understood. This study was conducted to assess the prevalence of timely breastfeeding initiation and associated factors in Dembecha district, North West Ethiopia.

Methods: A cross-sectional study design was conducted from August to September 2015. Multistage sampling techniques were used to select a total of 739 mothers who had children under 2 years of age. A pretested structured questionnaire was used to collect data. Descriptive analysis, bivariate and multiple logistic regression analysis were performed.

Results: The level of timely initiation of breastfeeding was $73.1 \%$. The magnitude of prelacteal feeding and colostrum feeding in this study was 11.9 and $76.2 \%$ respectively. Timely initiation of breastfeeding was significantly associated with the presence of four and above antenatal appointments during the last pregnancy (Adjusted Odds Ratio [AOR] 3.1; $95 \%$ Confidence Interval [CI] 1.2, 8.0), access to mass media such as radio or television (AOR 1.54; $95 \% \mathrm{Cl} 1.10,2.20$ ), and mothers who were attended by traditional birth attendant during their last birth (AOR 0.23; $95 \% \mathrm{Cl} 0.07,0.75$ ).

Conclusions: The level of timely initiation of breastfeeding was relatively good compared with previous studies in Ethiopia, although more than quarter of mothers didn't start breastfeeding within the first one hour of birth. Timely initiation of breastfeeding was significantly associated with the presence of four and above antenatal care during the last pregnancy, access to mass media (e.g. radio, television), and last child attended by traditional birth attendant. Programs should encourage mothers to use skilled birth attendants at birth, emphasise the importance of feeding colostrum and to initiate breastfeeding within one hour after childbirth.
\end{abstract}

Keywords: Breastfeeding, Timely initiation of breastfeeding, Child health, Ethiopia

\footnotetext{
* Correspondence: gechm2005@gmail.com

${ }^{3}$ Midwifery Department, Medicine and Health Sciences College, Debre

Markos University, Debre Markos, Ethiopia

Full list of author information is available at the end of the article
} 


\section{Background}

The timely initiation of breastfeeding is defined as putting the newborn baby to the breast within one hour of birth [1]. Breastfeeding is an important public health strategy to reduce infant, child and maternal morbidity and mortality and helps to control health care costs. Breastfeeding is associated with a reduced risk of otitis media, gastroenteritis, respiratory illness, sudden infant death syndrome, necrotizing enterocolitis, obesity, and hypertension [2].

Based on World Health Organization (WHO) report, globally over one million newborn infants could be saved each year by initiating breastfeeding within the first hour of life. In developing countries alone, early initiation of breastfeeding could save as many as 1.45 million lives each year by reducing deaths mainly due to diarrheal diseases and lower respiratory tract infections in children [3]. Studies have also reported that timely initiation of breastfeeding can reduce more than twenty percent of neonatal deaths [4]. In developing countries where the rate of communicable diseases is high, timely initiation of breastfeeding is important in reducing the diarrheal disease in the child [5].

According to study conducted in India, timely initiation of breastfeeding is recognized as the first and vital step toward reducing the infant and less than 5 years of age child mortality. It has the potential to prevent $16 \%$ of neonatal deaths if all infants are breastfed from day 1 , and $22 \%$ if breastfeeding is started within the first hour [6].

For several years, the poor nutritional status of children and women in Ethiopia has caused serious health problems [7]. Based on 2010 Federal Ministry of Health $(\mathrm{FMOH})$ report, the initiation of breastfeeding within one hour of birth was lowest in the Amhara and Somali regions (38 and $40 \%$, respectively), and highest in the South Nation Nationality of People (SNNP) and Dire Dawa regions (67 and $66 \%$, respectively [8]. A study conducted in south east Ethiopia showed the prevalence of timely initiation of breastfeeding to be $52.4 \%$. The study also showed that factors that were associated with timely breastfeeding initiation were being urban resident and getting postnatal counselling [9]. A community based cross-sectional study conducted in western Ethiopia also showed a better, $88.5 \%$ prevalence of timely breastfeeding initiation. Getting advice on breastfeeding during antenatal visits, women who knew the importance of colostrum and importance of mother to child attachment were the determinant factors which were associated with timely breastfeeding initiation [1].

Other studies have showed that problems related with the timely initiation of breastfeeding cause a rise in neonatal mortality of $22 \%$ [10]. This study will be conducted to assess the prevalence of the timely initiation of breastfeeding and associated factors in Dembecha Woreda, North West Ethiopia. The findings of this study will be important for planning and implementation of prevention strategies of child morbidity and mortality in resource limited setting.

\section{Methods}

\section{Study design, area and period}

A cross-sectional quantitative study was conducted in Dembecha Zuria Woreda, from August to September, 2015. Dembecha District is one of the fifteen Districts in West Gojjam zone of Amhara regional state, Ethiopia. Dembecha town is the capital town of Dembecha Zuria Woreda. The woreda is located $349 \mathrm{~km}$ north from the capital city of Addis Ababa and $215 \mathrm{~km}$ south from the regional capital town of Bahir Dar. The woreda has 25 rural kebeles and 4 urban kebeles [11]. Based on 2014/ 2015 Amhara Bureau of Finance and Economic Development Report, the total population of the district was estimated to be 151,020 . Of this, $49.5 \%$ were females and $50.5 \%$ were males. The total number of women who had a child less than 2 years of age in the woreda was 5434. The majority, $95 \%$ of the population follow Ethiopian Orthodox Christianity. The woreda has six health centres which provide healthcare services [11].

\section{Source and study population}

The source population were all mothers who had at least one child less than 2 years of age and were living in the woreda. Mothers who have a child less than 2 years of age, who are permanent residents, and who lived in the study area for at least six months, were included in the study.

\section{Sample size determination}

The required sample size of the study was determined by using a single population proportion formula with the following assumptions:

$\mathrm{n}=$ total number of mothers to be interviewed

$\mathrm{z}=$ critical value at $95 \%$ confidence interval (1.96)

$\mathrm{p}=$ prevalence of timely initiation of breastfeeding in under two children which is $57.2 \%$ in rural communities of Arba Minch Zuria [12].

$\mathrm{d}=$ marginal error between sample statistics and the population parameter $(5 \%)$

$$
\begin{aligned}
& \frac{\mathrm{n}=\left(\mathrm{z} \frac{\alpha}{2}\right)^{2} \mathrm{p}(1-\mathrm{p})}{\mathrm{d}^{2}} \\
& \mathrm{n}=\frac{1.96^{2} * 0.572 * 0.428}{0.05^{2}}=376
\end{aligned}
$$

Since the source population was 5434, less than 10,000 , the correction formula was used and gave the sample size 
of 352 , but since multistage sampling technique was used, the sample size is multiplied by the design effect to get the final sample size. By taking the design effect as two, the required sample size was 704. Additionally $5 \%$ was added for non-response rate giving a final sample size of 739 .

\section{Sampling procedure}

Multistage sampling technique was used to select the study population at the community level. The first 5 kebeles were selected from 25 kebele using simple random sampling technique. A sample size (739) of mothers who had a child less than 2 years old from each kebele was selected proportionally and each household was selected by systematic random sampling technique. Then, the number of house hold $(\mathrm{HH})$ with mothers and a child less than 2 years of age were selected from the sampled kebeles using the family folder registration book of each house hold, found in the health post. Based on the proportional allocation each sample was selected every unit of second household. In the case when more than one mother with in a household were available, a lottery method was used to select the mother to be included and if more than two under two year children were found in the house hold the youngest child was selected. The sampling procedure of children under 2 years of age in Dembecha Zuria Woreda is presented in Fig. 1.

\section{Variables of the study}

The dependent variable of this study is the timely initiation of breastfeeding, which means the initiation of breastfeeding within one hour after childbirth. The independent variables include; sociodemographic characteristics (age, religion, education of the mother, education of the husband, ethnicity, marital status, economic status/monthly income, sex of infant, age of infant, occupation of the mother, occupation of the husband and access to Media). Obstetric related history (parity,

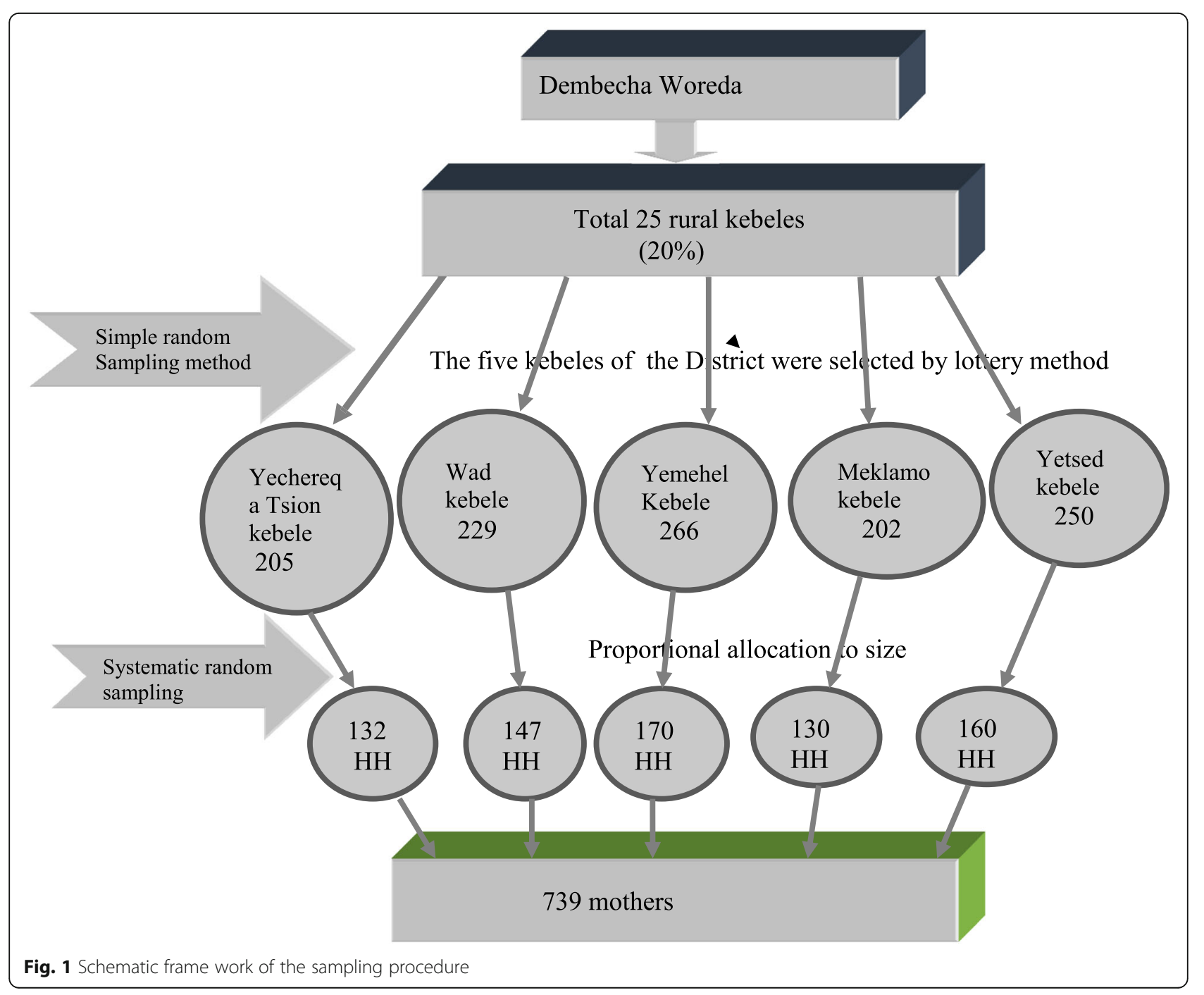


history and frequency of antenatal visits, counselling, place of delivery, mode of delivery, postnatal follow up, history of breast problems, and knowledge and attitude of the mother towards breastfeeding.

\section{Operational definitions Timely initiation of breastfeeding}

Is defined as putting the neonate on the mother's breast to suckle within one hour of birth as reported by the mother/caretaker of the child.

\section{Knowledge}

Iincluded breastfeeding initiation, and an awareness and understanding of the timely initiation of breastfeeding. Mothers were considered to have good knowledge if they correctly answered greater than or equal to $70 \%$ of the total knowledge related assessing questions.

\section{Attitude}

In this study is defined as the mothers overall favourableness toward the timely initiation of breastfeeding. Respondents were categorized as having a favourable attitude if the final score for attitude related questions was greater than or equal to $50 \%$. If respondents had a score of less than $50 \%$, they were grouped as having an unfavourable attitude towards the timely breastfeeding initiation.

\section{Traditional birth attendant}

Is defined when the childbirth was attended by an unskilled personnel such as relatives, neighbour, friend or unskilled community based birth attendants.

\section{Data collection tool and procedure}

The data collection questionnaire was prepared after reviewing different related literatures. The tools was first prepared in the English language, then translated to Amharic and translated back to English by another translator to check the consistence of the data. A pretested structured questionnaire was used to collect the required data from respondents. Data were collected by face-toface interview and supervision was based on prepared checklists. Five health extension workers were involved in the data collection and two nurses were assigned as supervisors.

\section{Data quality assurance}

The quality of data was assured by proper designing and pretest of the questionnaires in $5 \%$ (37 mothers) of the sample size in one kebele, other than the selected kebeles, with similar sociodemographic characteristics. Two days training was given for both data collectors and supervisors by the principal investigator before and after the pretest. The training was about the objectives of the study, contents of the questionnaire, data collection techniques and the issues of the confidentiality of the responses. Every day after data collection, the questionnaires were reviewed and checked for completeness by the supervisors and principal investigator and the necessary feedback was offered to the data collectors in the next morning.

\section{Data processing and analysis}

All the questionnaires were checked for completeness, coded and entered into EpiData version 3.1 and then exported to SPSS version 20 for data analysis. The descriptive statistics was presented in the form of tables and text using frequencies and numerical summary statistics such as mean and standard deviation. Variables in the bivariate analysis with $p$ - value $\leq 0.2$ were further considered in the final logistic regression analysis. The degree of association between independent and dependent variables was assessed by using odds ratio at $95 \%$ confidence interval.

\section{Results \\ Socio- demographic characteristics}

Seven hundred thirty nine mothers who had children less than 2 years of age were included in the study making the response rate of $100 \%$. Out of the total children, 400 $(54.1 \%)$ and 339 (45.9\%) of the children were males and female respectively. The mean $( \pm \mathrm{SD})$ age of the mother and the child were $31( \pm 6)$ years and $12( \pm 7)$ months respectively. Out of the total study participants, 475 $(64.3 \%)$ of mothers earn an average monthly income of less than 500birr, 336 (45.5\%) mothers were unable to read and write and only $453(61.3 \%)$ mothers have access to Media. The majority, 711 (96.2 \%) of respondents were married (Table 1).

\section{Health service and obstetrics related history}

Most, 710 (96.1\%) of the mothers attended an antenatal visit during their last pregnancy and 514 (69.6\%) of the mothers have history of three and above pregnancies. Eighty three percent of mothers gave birth to their previous baby at the health institution. More than $2 / 3$ of mothers had received postnatal care after their last delivery and 432 (58.5\%) of mothers received information about breastfeeding during antenatal visits (Table 2).

\section{Knowledge and attitude towards timely breastfeeding initiation}

The majority, $552(74.7 \%)$ of the respondents have good knowledge, while 187 (25.6\%) had poor knowledge about the timely breastfeeding initiation. The majority, $661(89.4 \%)$ of the respondents have a favourable attitude and 78 (10.6 \%) have unfavourable attitude towards the timely initiation of breastfeeding. 
Table 1 Socio-demographic characteristics of mothers who had a child less than 2 years of age in Dembecha Zuria Woreda, North West Ethiopia, 2015

\begin{tabular}{|c|c|c|}
\hline Variables $(n=739)$ & Frequency & Percent \\
\hline \multicolumn{3}{|l|}{ Maternal age } \\
\hline 15-19 year old & 15 & 2 \\
\hline $20-24$ & 84 & 11.4 \\
\hline $25-29$ & 223 & 30.2 \\
\hline $30+$ & 417 & 56.4 \\
\hline \multicolumn{3}{|l|}{ Child age in months } \\
\hline$<6$ months & 203 & 27.5 \\
\hline$\geq 6$ months & 536 & 72.5 \\
\hline \multicolumn{3}{|l|}{ Religion of the mother } \\
\hline Orthodox & 735 & 99.5 \\
\hline Muslim & 4 & 0.5 \\
\hline \multicolumn{3}{|l|}{ Maternal education } \\
\hline Unable to read and write & 336 & 45.5 \\
\hline Read and write & 332 & 44.9 \\
\hline Elementary (grade 1-8) & 48 & 6.5 \\
\hline High school (grade 9-12) & 19 & 2.6 \\
\hline College level and above & 4 & 0.5 \\
\hline \multicolumn{3}{|l|}{ Marital status } \\
\hline Married & 711 & 96.2 \\
\hline Single & 13 & 1.8 \\
\hline Divorced & 12 & 1.6 \\
\hline Widowed & 3 & 0.4 \\
\hline \multicolumn{3}{|l|}{ Occupation of the mother } \\
\hline Housewife & 682 & 92.3 \\
\hline Farmer & 12 & 1.6 \\
\hline Private work & 4 & 0.5 \\
\hline Daily laborer & 40 & 5.4 \\
\hline Others & 1 & 0.1 \\
\hline \multicolumn{3}{|l|}{ Husband's education } \\
\hline Unable read and write & 232 & 31.4 \\
\hline Read and write & 431 & 58.3 \\
\hline Elementary (1-8) & 46 & 6.2 \\
\hline High school (9-12) & 17 & 2.3 \\
\hline College and above & 13 & 1.8 \\
\hline \multicolumn{3}{|c|}{ Monthly income (in Ethiopian birr) } \\
\hline$<500.00$ birr & 475 & 64.3 \\
\hline 501.00-1499.00 birr & 181 & 24.5 \\
\hline$>1500.00$ birr & 83 & 11.2 \\
\hline \multicolumn{3}{|l|}{ Media access (radio/television) } \\
\hline Yes & 453 & 61.3 \\
\hline No & 286 & 38.7 \\
\hline
\end{tabular}

Table 2 Obstetric history of mothers who had a child under 2 years of age in Dembecha Zuria Woreda, North West Ethiopia, 2015

\begin{tabular}{|c|c|c|}
\hline Variables $(n=739)$ & Frequency & Percent \\
\hline \multicolumn{3}{|l|}{ Gravidity $(n=739)$} \\
\hline One & 100 & 13.5 \\
\hline Two & 125 & 16.9 \\
\hline Three \& above & 514 & 69.6 \\
\hline \multicolumn{3}{|c|}{ Antenatal visit in the last pregnancy $(n=739)$} \\
\hline Yes & 710 & 96.1 \\
\hline No & 29 & 3.9 \\
\hline \multicolumn{3}{|c|}{ Number of antenatal visits in the last pregnancy } \\
\hline One & 22 & 3.00 \\
\hline Two-three & 275 & 37.2 \\
\hline Four \& above & 413 & 55.9 \\
\hline \multicolumn{3}{|c|}{ Breastfeeding counseling during antenatal appointments $(n=739)$} \\
\hline Yes & 432 & 58.5 \\
\hline No & 278 & 37.6 \\
\hline \multicolumn{3}{|l|}{ Place of delivery $(n=739)$} \\
\hline Health facility & 612 & 82.8 \\
\hline Home & 127 & 17.2 \\
\hline \multicolumn{3}{|l|}{ Attended at birth } \\
\hline Traditional birth attendant & 121 & 16.4 \\
\hline Health professionals & 618 & 83.6 \\
\hline \multicolumn{3}{|l|}{ Postnatal visit $(n=739)$} \\
\hline Yes & 562 & 76.0 \\
\hline No & 177 & 24.0 \\
\hline \multicolumn{3}{|c|}{ Breastfeeding counseling during postnatal visit $(n=739)$} \\
\hline Yes & 556 & 75.2 \\
\hline No & 7 & 0.9 \\
\hline \multicolumn{3}{|c|}{ History of infant admission ( $n=739)$} \\
\hline Yes & 59 & 8.0 \\
\hline No & 680 & 92.0 \\
\hline \multicolumn{3}{|c|}{ History of breast problems $(n=739)$} \\
\hline Yes & 62 & 8.4 \\
\hline No & 677 & 96.1 \\
\hline
\end{tabular}

\section{Breastfeeding practice}

The level of timely initiation of breastfeeding was 540 (73.1\%) and the majority, 725 (98.1\%) of mothers ever breastfed. More than two thirds, 563 (76.2 \%) of mothers fed their colostrum, 87 (11.8\%) of the mothers were giving the child foods other than breast milk in the first six months after delivery; 61 (70.1\%) mothers gave water, 17 (2.3\%) mothers gave butter, 4 (0.5 \%) gave glucose water and $5(0.7 \%)$ mothers gave other food. The majority, 569 (77 \%) of mothers have received breastfeeding advice and the majority, 533 (72.1\%) of 
mothers were advised by health professionals. Two hundred and three mother's breastfed their child when the child cries and $736(99.6 \%)$ mothers were still breastfeeding their child (Table 3).

Table 3 Breastfeeding practice of mothers who had a child less than 2 years of age in Dembecha Zuria Woreda, North West Ethiopia, 2015

\begin{tabular}{|c|c|c|}
\hline Variables $(n=739)$ & Frequency & Percent \\
\hline \multicolumn{3}{|c|}{ Did you breastfeed your last child? } \\
\hline Yes & 725 & 98.1 \\
\hline No & 14 & 1.9 \\
\hline \multicolumn{3}{|c|}{ Did you breastfeed within one hour? } \\
\hline Yes & 540 & 73.1 \\
\hline No & 199 & 26.9 \\
\hline \multicolumn{3}{|c|}{ Did you feed your colostrum to your last child? } \\
\hline Yes & 563 & 76.2 \\
\hline No & 176 & 23.8 \\
\hline \multicolumn{3}{|c|}{ Did you use prelacteal foods with your last child? } \\
\hline Yes & 87 & 11.8 \\
\hline No & 652 & 88.2 \\
\hline \multicolumn{3}{|c|}{ If yes, what types of prelacteal food did you use? } \\
\hline Butter & 17 & 2.3 \\
\hline Water & 61 & 8.3 \\
\hline Glucose water & 4 & 0.5 \\
\hline Others & 5 & 0.7 \\
\hline \multicolumn{3}{|c|}{ When do you breastfeed this last child? } \\
\hline On demand & 457 & 61.8 \\
\hline When the child cries & 273 & 36.9 \\
\hline Other & 9 & 1.2 \\
\hline \multicolumn{3}{|l|}{ Do you still breastfeed? } \\
\hline Yes & 736 & 99.6 \\
\hline No & 3 & 0.4 \\
\hline \multicolumn{3}{|c|}{ Any breastfeeding difficulty with your last child? } \\
\hline Yes & 115 & 15.6 \\
\hline No & 624 & 84.4 \\
\hline \multicolumn{3}{|c|}{ Breastfeeding frequency of your last child } \\
\hline Every $\leq 2 \mathrm{~h}$ & 383 & 51.8 \\
\hline Every $>2 \mathrm{~h}$ & 356 & 48.2 \\
\hline \multicolumn{3}{|c|}{ Did you receive counseling about breastfeeding with your last child? } \\
\hline Yes & 569 & 77 \\
\hline No & 170 & 23 \\
\hline \multicolumn{3}{|c|}{ Who advised you about breastfeeding? } \\
\hline Health professional & 533 & 72.1 \\
\hline Friend & 23 & 3.1 \\
\hline Family & 13 & 1.8 \\
\hline
\end{tabular}

Factors associated with timely initiation of breastfeeding Bivariate and multivariate analyses were conducted. On bivariate analysis, factors which were associated with timely initiation of breastfeeding include; Media access (like radio and/or television), number of antenatal visits during the last pregnancy, place of delivery of the last child, attitude of respondents towards timely breastfeeding initiation, and traditional birth attendance. Candidate variables for multivariate analysis were entered to multiple logistic regression analysis and variables which were found to be associated with timely breastfeeding initiation include; the presence of four and above antenatal visits during the last pregnancy (AOR 3.1, $95 \% \mathrm{CI}$ $1.2,8$ ), access to mass media (AOR 1.54, $95 \%$ CI 1.10, 2.20), and presence of a traditional birth attendant during childbirth (AOR 0.23, $95 \%$ CI 0.07, 0.75) (Table 4).

\section{Discussion}

The findings of this study showed that the overall level of timely initiation breastfeeding of mothers who had less than 2 years of age were 540 (73.1\%). This was much lower than the Ethiopian Ministry of Health target to increase breastfeeding within the first hour of life to $92 \%$ by 2015 [8]. The finding is also lower that a study conducted in Bahir Dar town (87.0\%) [13], and Australia $98 \%$ [14] and slightly lower than Saudi Arabia (77.8 \%) [15]. The finding was slightly higher than those observed in other studies from South Nation Nationality of People (67\%), Dire Dawa (66\%), and Nepal (66.4 \%) $[8,16-21]$. This difference may be due to health policy difference among the countries and due to the difference in sociodemographic characteristics. In addition, the current study was conducted in a relatively rural area when compared with the above mentioned studies. This finding is also similar with a study conducted in Goba town [9].

Only $76.2 \%$ of women reported that they feed their colostrum to their child, while $23.8 \%$ discarded their colostrum before breastfeeding. The finding of this study is lower than a study in Axum, in which only $55 \%$ didn't express and discard their colostrum [20]. The possible explanations for such difference could be due to the difference in sociodemographic and study period; the current study was conducted after large scale educational programs on the importance of feeding colostrum during the recent years.

The magnitude of prelacteal feeding in this study was $11.9 \%$. Compared to other studies, this finding is almost similar with a study done in Axum, in which the prevalence of prelacteal feeding was $11.72 \%$ [20]. The finding is relatively lower than the study done in India, $16.9 \%$ [6].

The multivariate logistic regression model found three factors associated with timely initiation of breastfeeding. 
Table 4 Multivariable logistic regression analysis showing factors associated with timely initiation of breastfeeding among mothers who had a child less than 2 years of age in Dembecha Zuria Woreda, North West Ethiopia, 2015

\begin{tabular}{|c|c|c|c|c|c|c|}
\hline \multirow[t]{2}{*}{ Variables } & & \multicolumn{2}{|c|}{ Timely initiation of breastfeeding } & \multirow[t]{2}{*}{ COR $(95 \% \mathrm{Cl})$} & \multirow[t]{2}{*}{ AOR $(95 \% \mathrm{Cl})$} & \multirow[t]{2}{*}{$p$-value } \\
\hline & & $\begin{array}{l}\text { Within } 1 \mathrm{~h} \text { of } \\
\text { childbirth } \\
\mathrm{n}(\%)\end{array}$ & $\begin{array}{l}\text { After } 1 \mathrm{~h} \text { of } \\
\text { childbirth } \\
\mathrm{n}(\%)\end{array}$ & & & \\
\hline \multirow[t]{3}{*}{ Number of antenatal visits } & 1 visit & $9(40.9 \%)$ & $13(59.1 \%)$ & 1 & 1 & \\
\hline & $2-3$ & $180(65.5 \%)$ & $95(34.5 \%)$ & $2.74(1.13,6.64)^{*}$ & $1.74(0.68,4.42)$ & 0.248 \\
\hline & $\geq 4$ & $330(79.9 \%)$ & $83(20.1 \%)$ & $5.74(2.37,13.89)^{*}$ & $3.1(1.2,8)$ & $0.019^{*}$ \\
\hline \multirow{2}{*}{$\begin{array}{l}\text { Access to mass Media } \\
\text { (e.g.: radio, television) }\end{array}$} & Yes & $349(77 \%)$ & $104(23 \%)$ & $0.59(0.43,0.93)^{*}$ & $1.54(1.1,2.2)$ & $0.018^{*}$ \\
\hline & No & $191(66.8 \%)$ & $95(33.2 \%)$ & 1 & 1 & \\
\hline \multirow[t]{2}{*}{ Place of delivery of the last child } & Health facility & $470(76.8 \%)$ & $142(23.2 \%)$ & $2.7(1.8,4.01)^{*}$ & $1.84(0.564,5.988)$ & 0.312 \\
\hline & Home & $70(55.1 \%)$ & $57(44.9 \%)$ & 1 & 1 & \\
\hline \multirow{2}{*}{$\begin{array}{l}\text { Attitude towards timely initiation } \\
\text { of breastfeeding }\end{array}$} & Unfavorable attitude & $373(75.7 \%)$ & $120(24.3 \%)$ & 1 & 1 & \\
\hline & Favorable attitude & $167(67.9 \%)$ & $79(32.1 \%)$ & $0.68(0.49,0.95)^{*}$ & $1.34(0.93,1.92)$ & 0.118 \\
\hline \multirow[t]{2}{*}{ Last child birth attended by } & Skilled birth attendant & $62(51.2 \%)$ & $59(48.8 \%)$ & 1 & 1 & \\
\hline & Traditional birth attendant & $478(77.3 \%)$ & $140(22.7 \%)$ & $3.25(2.17,4.86)^{*}$ & $0.23(0.07,0.75)$ & $0.014^{*}$ \\
\hline
\end{tabular}

AOR adjusted odd ratio, COR crude odd ratio

*Statistical significance at $(p-$ value $<0.05), 1$ : reference group

These variables include; the presence of four and above antenatal appointments during the last pregnancy, access to mass media (e.g. radio, television), and traditional birth attendance during their last birth.

Mothers who had four and above antenatal care visits during their previous pregnancy were three times more likely to initiate breastfeeding within one hour after childbirth (AOR 3.1, $95 \%$ CI 1.2, 8). This could be because mothers who had frequent antenatal care visits during their pregnancy could access frequent counselling sessions on the importance of timely initiation of breastfeeding, and thereby be more likely to practice it. This finding is supported by a study done in western Ethiopia and in India, which showed that counselling on breastfeeding during antenatal visits increases the rate of timely initiation of breastfeeding by mothers $[1,6,22]$. This is because the mother becomes receptive and prepares herself for timely breastfeeding [6]. The findings are also similar with the findings of large scale community based programs as conducted in Bolivia and Madagascar [23].

Mothers who had access to mass medias like radio, and/or television were more than 1.5 times more likely to initiate breastfeeding within one hour after childbirth (AOR 1.54, 95 \% CI 1.1, 2.2). This maybe because the information obtained from such channels regarding breastfeeding improves their knowledge and practice.

Several studies have showed that the use of a skilled birth attendant during childbirth is important in reducing the high level of child and maternal morbidity and mortality especially in developing countries [24-26]. The current study also found that women who were attended by a traditional birth attendant during their last childbirth were less likely to start breastfeeding within one hour after birth (AOR 0.23, $95 \%$ CI 0.07, 0.75). The possible explanation for this could be difference in the health education provided by health professionals as part of labour and delivery care, and immediately after child birth when compared with traditional birth attendants.

The study had certain limitations. The limited nature of the cross-sectional study design in determining causeeffect relationship, and recall bias may be introduced since this study also included mothers who experienced childbirth before the 2 years of the data collection period.

\section{Conclusions}

Although some improvements have been observed, the study showed that the level of timely initiation of breastfeeding is still low. Even though a large number of women are feeding their babies their colostrum, a significant is the number of women are still discarding their colostrum before initiating breastfeeding. Timely initiation of breastfeeding was positively associated with the presence of four and above antenatal care visits during the previous pregnancy, and access to mass media (e.g. radio, television). In addition, women whose last child was attended by a traditional birth attendant were less likely to initiate breastfeeding within the first one hour after birth. Community based programs focusing on improving knowledge of mothers towards timely breastfeeding initiation is important. Policy makers should give emphasis on the factors mentioned above when designing interventions to improve the practice on timely breastfeeding initiation. Further studies should be conducted on a larger scale for reasons of not feeding colostrum. 


\section{Abbreviations}

AOR: Adjusted odd ratio; COR: Crude odd ratio; FMOH: Federal Ministry of Health; TBA: Traditional birth attendant; WHO: World Health Organization

\section{Acknowledgements}

We would like to acknowledge to Debre Markos University, College of Medicine and Health Science, to GAMBY College of Medical sciences, supervisors, data collectors and study participants.

\section{Funding}

No funding was obtained for this study.

\section{Availability of data and material}

The datasets analysed during the current study available from the corresponding author on reasonable request.

\section{Authors' contributions}

AB participated in the design, data collection, data analysis and interpretation. GM and MT also participated in the analysis, interpretation and drafting of the manuscript. All authors read and approved the final manuscript.

\section{Competing interests}

The authors declare that they have no competing interests.

\section{Consent for publication}

Not applicable

\section{Ethics approval and consent to participate}

Ethical approval was obtained from the institutional ethical review board of Debre Markos University, College of Medicine and Health Science. Dembecha District Health Office and the selected kebeles for the study were communicated through an official letter written from the Debre Markos University. After informing the purpose and objective of the study, informed verbal consent were obtained from each study participants. Participation was on voluntary basis and participants could withdraw from participation at any time if they feel uncomfortable. The information collected for this study was kept confidential.

\section{Author details}

${ }^{1}$ Save the Children International, Bahirdar, Ethiopia. ${ }^{2}$ Public Health Department, Medicine and Health Sciences College, Debre Markos University, Debre Markos, Ethiopia. ${ }^{3}$ Midwifery Department, Medicine and Health Sciences College, Debre Markos University, Debre Markos, Ethiopia.

\section{Received: 6 June 2016 Accepted: 26 September 2016}

Published online: 06 October 2016

\section{References}

1. Wolde T, Birhanu T, Ejeta E. Prevalence and determinants of timely initiation of breastfeeding among lactating mothers of urban dwellers in western Ethiopia. Food Sci Qual Manag. 2014;31(2225-0557):110.

2. Bayissa ZB, Gelaw BK, Geletaw A, Abdella A, Chinasho B, Alemayehu A, et al. Knowledge and practice of mothers towards exclusive breastfeeding and its associated factors in Ambo woreda west shoa zone oromia region, ethiopia. Epidemiology. 2015;5(1):1-7.

3. Jana AK. Interventions for promoting the initiation of breastfeeding Geneva: The WHO reproductive health library; 2009. p. 2.

4. Edmond KM, Zandoh C, Quigley MA. Delayed breastfeeding initiation increases risk of neonatal mortality. Pediatrics. 2006;117:380-6.

5. Adhikari, et al. Factors associated with early initiation of breastfeeding among Nepalese mothers: further analysis of Nepal Demographic and Health Survey, 2011. Int Breastfeed J. 2014:9:21.

6. Patel A, Banerje A, Kaletwad A. Factors associated with prelacteal feeding and timely initiation of breastfeeding in hospital-delivered infants in India. J Hum Lact. 2013;29(4):572-8

7. Central Statistical Agency. Ethiopian demographic and health survey. Calverton: ICF International; 2012.

8. Federal ministry of health. Health sector development program IV Woreda based annual core plan. 2010.
9. Setegn T, Gerbaba M, Belachew T. Determinants of timely initiation of breastfeeding among mothers in Goba Woreda, South East Ethiopia: a cross sectional study. BMC Public Health. 2011;11:217.

10. Hegney D, Fallon T, Crepinsek M, O'Brien M. The baby-friendly hospital initiative and breastfeeding duration: relating the evidence to the Australian context. Birth Issues. 2005;14(3):90-5.

11. West Gojam Zone Annual plan. Un published report. 2014

12. Adugna DT. Women's perception and risk factors for delayed initiation of breastfeeding in Arba Minch Zuria, Southern Ethiopia. Int Breastfeed J. 2014;9:8.

13. Seid AM. Vaginal delivery and maternal knowledge on correct breastfeeding initiation time as predictors of early breastfeeding initiation. ISRN Epidemiology. 2014;2014:3-5.

14. McLachlan HL, Forster DA. Initial breastfeeding attitudes and practices of women born in Turkey, Vietnam and Australia after giving birth in Australia. Int Breastfeed J. 2016;1:7.

15. Amin T, Hablasa H, Qader AAA. Determinants of initiation and exclusivity of breastfeeding in Al Hassa, Saudi Arabia. Int Nurs Rev. 2010;6(2):59-68.

16. Ekambaram M, Bhat B, Vishnu B, Padiyath Ahamed MA. Knowledge, attitiude and practice of breastfeeding among postnatal mothers. Curr Pediatr Res. 2010;14(2):119-24.

17. Wren $\mathrm{H}$, Chambers L. Breastfeeding in Cambodia: mother knowledge, attitudes and practices. World Health Popul. 2011;13(1):17-29.

18. Vieira TO, Vieira GO, Giugliani ERJ, Mendes CM, Martins CC, Silva LR Determinants of breastfeeding initiation within the first hour of life in a Brazilian population. BMC Public Health. 2010;10:760.

19. Örün E, Yalçın SS, Madenda Y, Üstünyurt-Eras Z, Kutluk S, Yurdakök K. Factors associated with breastfeeding initiation time in a Baby-Friendly Hospital. Turk J Pediatr. 2010;5:10-6.

20. Alemayehu M, Abreha K, Yebyo H, Zemichael K, Gebremichael H. Factors associated with timely initiation and exclusive breast feeding among mothers of Axum town, Northern Ethiopia. Sci J Public Health. 2014;2(5): 394-401.

21. Bobhate PS, Shrivastava SR. Breastfeeding practices and factors associated with it: a cross sectional study among tribal women in Khardi primary health centre, Thane, India. Int J Public Health Res. 2012;2(1):115-21.

22 Wolde T, Birhanu T, Ejeta E. Prevalence and determinants of timely initiation of breastfeeding among lactating mothers of urban dwellers in western Ethiopia: a community based cross sectional study. Food Sci Qual Manag. 2014;31:110-6.

23 Baker EJ, Sanei LC, Franklin N. Early initiation of and exclusive breastfeeding in large-scale community-based programmes in Bolivia and Madagascar. J Health Popul Nutr. 2006;24(4):530-9.

24 Teferra AS, Alemu FM, Woldeyohannes SM. Institutional delivery service utilization and associated factors among mothers who gave birth in the last 12 months in Sekela District, North West of Ethiopia: a community based cross sectional study. BMC Pregnancy Childbirth. 2012;12:74.

25 Feyissa TR, Genemo GA. Determinants of institutional delivery among childbearing age women in Western Ethiopia, 2013: Unmatched case control study. PLoS One. 2014;9(5):e97194.

26 Abeje G, Azage M, Setegn T. Factors associated with Institutional delivery service utilization among mothers in Bahir Dar City administration, Amhara region: a community based cross sectional study. Reprod Health. 2014;11:22. 